\title{
A mulher no mundo do trabalho: a escolha do curso "masculino" e a inserção no
}

\author{
estágio \\ Women in the world of work: choosing the "male" course and entering the internship \\ La mujer en el mundo del trabajo: elegir el curso "masculino" e ingresar a las prácticas
}

Recebido: 24/09/2021 | Revisado: 03/10/2021 | Aceito: 07/10/2021 | Publicado: 10/10/2021

Paulete Constantino Cerqueira

ORCID: https://orcid.org/0000-0002-9570-4785

Instituto Federal de Educação, Ciência e Tecnologia de Alagoas, Brasil

E-mail: paulete.cerqueira@ifal.edu.br

Edel Alexandre Silva Pontes

ORCID: https://orcid.org/0000-0002-9782-8458

Instituto Federal de Educação, Ciência e Tecnologia de Alagoas, Brasil

E-mail: edel.pontes@ifal.edu.br

Beatriz Medeiros de Melo

ORCID: https://orcid.org/0000-0003-3128-3093

Instituto Federal de Educação, Ciência e Tecnologia de Alagoas, Brasil

E-mail: beatriz.melo@ifal.edu.br

\begin{abstract}
Resumo
A escolha da mulher por estudar em um curso de uma área tradicionalmente masculina (Segurança do Trabalho) e a sua inserção no estágio constituem o tema deste trabalho, escrito a partir de uma pesquisa que foi realizada no ambiente escolar do Instituto Federal de Alagoas (IFAL) - Campus São Miguel dos Campos. O seu objetivo é compreender os aspectos sócio-histórico-emocionais que envolvem essa escolha e conhecer a realidade das mulheres ao realizar o estágio, etapa crucial para a consolidação dos ensinamentos do curso e para a empregabilidade das mesmas. A pesquisa também visa ampliar o debate no IFAL, focando as questões de gênero, ensino e trabalho. O estudo investigativo é caracterizado como uma pesquisa-ação, de cunho quanti-qualitativo, e os instrumentos metodológicos utilizados foram o questionário semiestruturado e a roda de conversa. Os dados apontam para a necessidade de ampliar as pesquisas envolvendo a temática gênero e EPT, no sentido de pensar a educação como promotora de pensamento crítico, para estimular discussões e práticas que fortaleçam a equidade de gênero, no IFAL e na sociedade.
\end{abstract}

Palavras-chave: Gênero; Educação profissional e tecnológica; Trabalho.

\begin{abstract}
The choice of women to study in a course in a traditionally male area (Occupational Safety) and their inclusion in the internship are the theme of this work, written from a survey that was carried out in the school environment of the Federal Institute of Alagoas (IFAL) - São Miguel dos Campos Campus. Its objective is to understand the sociohistorical-emotional aspects that involve this choice and to get to know the reality of women when performing the internship, a crucial step for the consolidation of the course's teachings and for their employability. The research also aims to broaden the debate at IFAL, focusing on issues of gender, education and work. The investigative study is characterized as an action-research, with a quanti-qualitative nature, and the methodological instruments used were the semi-structured questionnaire and the conversation wheel. The data point to the need to expand research involving gender and EPT, in order to think of education as a promoter of critical thinking, to stimulate discussions and practices that strengthen gender equity, in IFAL and in society.
\end{abstract}

Keywords: Gender; Professional and technological education; Work.

\section{Resumen}

La elección de las mujeres para estudiar en un curso en un área tradicionalmente masculina (Seguridad Laboral) y su inclusión en la pasantía son el tema de este trabajo, elaborado a partir de una encuesta que se realizó en el ámbito escolar del Instituto Federal de Alagoas (IFAL) - Campus São Miguel dos Campos. Su objetivo es comprender los aspectos socio-histórico-emocionales que implican esta elección y conocer la realidad de las mujeres a la hora de realizar las prácticas, un paso crucial para la consolidación de las enseñanzas del curso y para su empleabilidad. La investigación también tiene como objetivo ampliar el debate en IFAL, centrándose en temas de género, educación y trabajo. El estudio investigativo se caracteriza por ser una investigación-acción, de carácter cuanti-cualitativo, y los instrumentos metodológicos utilizados fueron el cuestionario semiestructurado y la rueda de conversación. Los datos apuntan a la necesidad de ampliar la investigación que involucre género y EPT, para pensar en la educación como 
promotora del pensamiento crítico, para estimular discusiones y prácticas que fortalezcan la equidad de género, en IFAL y en la sociedad.

Palabras clave: Género, Educación profesional y tecnológica, Trabajo.

\section{Introdução}

O objetivo deste artigo é conhecer os motivos que levaram à escolha do Curso Técnico Subsequente em Segurança do Trabalho por mulheres, após a conclusão do ensino médio, no Instituto Federal de Alagoas, Campus São Miguel dos Campos e levantar dados acerca de como acontece à inserção das alunas no estágio. Para tanto, seu ponto de partida é compreender os aspectos sócio-históricos da dinâmica de reprodução do capital, como influenciaram o processo de inserção (ou não inserção) da mulher no mundo do trabalho e como a educação omnilateral pode influenciar neste cenário.

O fortalecimento na luta pelos direitos das mulheres é um tema contemporâneo, fundamental para a redução da desigualdade. Pesquisadores de diversas áreas do conhecimento vêm desenvolvendo trabalhos acadêmicos e científicos de forma a avaliar as diferenciações entre o "trabalho masculino" e o "trabalho feminino", como podemos ver em Daniel (2011, p324):

[...] é crescente a participação de mulheres em diferentes ocupações, até mesmo naquelas que anteriormente estiveram restritas a homens, como a Engenharia e a Medicina. No entanto, no seio das transformações se conservam algumas permanências. (Daniel, 2011, p.324).

A demarcação desses espaços de trabalho de forma seletiva e a precarização do trabalho das mulheres continuam presentes de forma acentuada, assinala Nascimento (2014, p.40):

O crescimento do desemprego e dos postos de trabalho de subcontratação, temporário, com jornada parcial e com menores rendimentos, concentra, principalmente, a mão de obra feminina. Essa realidade é permeada, fundamentalmente, pelas desigualdades de gênero construídas social e culturalmente, configurando as identidades de masculino e feminino, bem como os espaços a serem ocupados pelos sexos, ou seja, a definição do espaço privado para as mulheres e a esfera pública para os homens. (Nascimento, 2014, p.40).

Para entender melhor essa questão, faz-se necessário percorrer historicamente alguns momentos que trazem reflexões essenciais para o desenvolvimento do projeto, tais como: a importância do trabalho na vida humana, em suas dimensões ontológica, epistemológica e ético-política; a importância do papel a ser desempenhado pela educação omnilateral na formação para o trabalho, como princípio educativo, e por último, mas de forma alguma menos importante, a dimensão da relação capital na estratificação precarizada do trabalho feminino e, em consequência, no seu papel social subalterno.

A legislação educacional brasileira, tomando, por exemplo, a LDB (Lei de Diretrizes e Bases para a Educação, não aborda as questões de gênero. A LDB (Lei de Diretrizes e Bases para a Educação, de 1996) determina que o ensino será ministrado, entre outros princípios, pelo "respeito à liberdade e o apreço à tolerância" (BRASIL, 1996), sem especificar a que se refere quando fala em liberdade, nem determinar como se manifestaria esse apreço e muito menos o objeto da tolerância preconizada. Não é mencionada na LDB a questão de gênero, como sendo importante especificar que é necessário haver equidade entre alunos e alunas. Aliás, em nenhum momento do texto da lei de 61 páginas se fala na estudante nem nas alunas no feminino, como acontecia em 1996, quando foi promulgada.

Neste viés, é imprescindível pensar no tema quando se estuda a educação profissional e tecnológica, pois historicamente o Brasil se inseriu de forma subordinada aos centros hegemônicos do capital, na divisão internacional do trabalho produzida com a internacionalização do modo de produção capitalista (Pereira, M., 2010). Dentro desta inserção, o trabalho feminino ainda é - e sempre foi - mal pago, precarizado e menos valorizado (Brasil, 2018a). 
Luxemburgo (1914, p.1) descreveu essa situação em seu texto "A Proletária" a história da mulher no mundo do trabalho:

A mulher do povo teve de trabalhar pesado desde sempre. Na horda bárbara ela carrega o peso, coleta alimentos; no povoado primitivo, planta e mói o cereal, faz panelas; na Antiguidade, como escrava, serve os senhores e amamenta os rebentos; na Idade Média, fiava para o senhor feudal. Mas, desde que existe a propriedade privada, na maioria das vezes a mulher do povo trabalha separada da grande oficina na produção social, ou seja, separada também da cultura, encurralada na estreiteza doméstica de uma pobre existência familiar. [...] É apenas na proletária moderna que a mulher se toma um ser humano, pois é apenas a luta que produz o ser humano, a participação no trabalho cultural, na história da humanidade (Luxemburgo, 1914, p.1).

Ainda sobre essa revisita histórica, Engels escreveu que o papel da mulher na sociedade está inscrito na história da família, e esta se insere no surgimento da propriedade privada e do Estado. Ele pontua que a sociedade antiga, baseada em uniões gentílicas, desaparece, em virtude do aparecimento das novas classes sociais, transformando-se em uma nova sociedade organizada em Estado, em que "o regime familiar está completamente submetido às relações de propriedade e na qual têm livre curso as contradições de classe e a luta de classes, que constituem o conteúdo de toda a história escrita até os nossos dias" (Engels, 1984, p. 3).

Marx aborda de forma crítica a visão social, econômica e política da manobra masculina que subverteu o direito de herança materna, que resultou na passagem ao patriarcado e estabeleceu a condição inferior à mulher: "Casuística inata nos homens a de mudar as coisas mudando-lhe os nomes! E achar saídas para romper com a tradição sem sair dela, sempre que um interesse direto dá o impulso suficiente para isso" (Marx, apud Engels, 1984, p. 60).

No Brasil, a colonização se inicia com "o estabelecimento de uma economia dependente, servindo aos interesses de um florescente capitalismo mercantil europeu" (Saffioti, 2013, p. 203). A economia escravocrata brasileira caracterizou-se como exportadora de produtos primários, assumindo um papel bem delineado na comunidade capitalista internacional, “sempre dependente (...) do país ou países dominantes do referido sistema (internacional)” (Furtado, apud Saffioti, 2013, p. 204). Através dos mais de trezentos anos de escravidão como no estabelecimento do modo capitalista de produção de mão de obra assalariada e, de resto, até os dias atuais,

[...] a economia brasileira foi sempre determinada de fora, (...) sua história é a de uma constante e renovada rearticulação no sistema capitalista internacional, no qual sempre coube ao Brasil (...) a posição de uma peça auxiliar da engrenagem de um sistema autopropulsor (Saffioti, 2013, p. 205).

Nos primórdios da sociedade brasileira, era universal entre as mulheres "a aceitação da completa supremacia do homem sobre a mulher no grupo familial e na sociedade em geral” (Saffioti, 2013, p. 246). A mulher era privada do direito à propriedade territorial e, quando enviuvava, herdava a terça parte dos bens. Entretanto, se a viúva se casasse novamente, perdia a herança e o direito a criar os filhos do primeiro casamento. As mulheres só tiveram o direito a votar garantido em 1932, por um decreto do presidente Vargas (Brasil, 2020).

A divisão sexual do trabalho apresenta variações em diferentes épocas e países, explica Da Silva: "A forma como as sociedades organizam as relações de gênero e a divisão sexual do trabalho varia no tempo e no espaço, isto é, são construídas social e historicamente" (Da Silva, 2019, p.123). Ainda a esse respeito, Federici contextualiza a relação desta divisão com o advento do sistema capitalista: "A construção de uma nova ordem patriarcal, que tornava as mulheres servas da força de trabalho masculina, foi de fundamental importância para o desenvolvimento do capitalismo" (Federici, 2017, p.232).

A situação da mulher no Brasil, em relação ao homem, permanece desigual. Aqui, a mulher estuda mais, trabalha mais e ganha menos do que o homem, segundo o IBGE (Brasil, 2018a). Em 2016, as mulheres na faixa etária entre 15 a 17 anos de 
idade tinham frequência escolar líquida (ou seja, frequentavam escola no nível de ensino apropriado à sua faixa etária) de 73,5\% para o ensino médio, enquanto os homens perfaziam 63,2\% (Brasil, 2018a).

Na questão do trabalho, as mulheres contam três horas a mais, por semana, do que os homens, combinando trabalhos remunerados, cuidados com pessoas e afazeres no lar. Possuindo mais anos de escolaridade e trabalhando mais horas, elas ainda recebem, em média, 76,5\% do salário que os homens recebem pelo mesmo trabalho. Com nível superior completo ou maior, a diferença era ainda maior: as mulheres recebiam 63,4\% do rendimento dos homens em 2016 (Brasil, 2018a).

No aspecto educacional, os índices relativos às mulheres vêm mostrando a sua presença crescente e majoritária. Sobre essa afirmativa, afirma Quirino (2012, p.95):

No Brasil, ao longo do século XX e nos dez primeiros anos do século XXI, o acesso à escola foi sendo ampliado para os diferentes grupos populacionais antes excluídos do processo educacional formal. Com isto, as mulheres passaram a ter a oportunidade de estudar, o que hoje em dia se reflete na maior positividade dos indicadores educacionais, nos quais as mulheres vêm superando os homens (Quirino, 2012, p. 95).

Segundo os mais recentes dados do Instituto Nacional de Estudos e Pesquisas Educacionais Anísio Teixeira (INEP),

As mulheres são maioria nos cursos profissionais da Educação Básica. Dados do Censo Escolar 2018, do Instituto Nacional de Estudos e Pesquisas Educacionais Anísio Teixeira (Inep), mostram a predominância de alunas em todas as faixas etárias, com exceção dos alunos com mais de 60 anos. A maior diferença observada entre os sexos está na faixa de 40 a 49 anos, em que 60,7\% das matrículas são de mulheres. Para o Censo Escolar, educação profissional engloba cursos de formação inicial e continuada ou de qualificação profissional articulado à EJA ou ao ensino médio; ou cursos técnicos de nível médio nas formas articuladas (integrada ou concomitante) ou subsequente ao ensino médio. (Brasil, 2018b)

Essa tendência constatada nacionalmente no Censo Escolar também pode ser verificada em nosso campo de pesquisa. De 2016 a 2021, a porcentagem de candidatas no Campus São Miguel dos Campos vem sendo maior do que a dos candidatos do gênero masculino, bem como a de aprovadas no concurso, como pode ser observado nas tabelas a seguir:

Tabela 1: Inscrições nos processos seletivos no Campus São Miguel dos Campos.

\begin{tabular}{ccccccc}
\hline Inscritos/as & 2016 & 2017 & 2018 & 2019 & 2020 & 2021 \\
Homens & 219 & 175 & 133 & 132 & 63 & 180 \\
Mulheres & 395 & 321 & 201 & 331 & 158 & 306 \\
TOTAL & 614 & 496 & 334 & 463 & 221 & 486 \\
\hline
\end{tabular}

Fonte: IFAL (2021).

Com os dados das inscrições em mãos, passamos a compará-los com os dados das aprovações.

Tabela 2: Aprovações nos processos seletivos no Campus São Miguel dos Campos.

\begin{tabular}{crrrrrr}
\hline Aprovados/as & 2016 & 2017 & 2018 & 2019 & 2020 & 2021 \\
Homens & 67 & 57 & 67 & 55 & 28 & 27 \\
Mulheres & 93 & 103 & 93 & 105 & 52 & 53 \\
TOTAL & 160 & 160 & 160 & 160 & 80 & 80 \\
\hline
\end{tabular}

Fonte: IFAL (2021). 
Os dados apontam que, em seis anos, a média de mulheres inscritas para os concursos de seleção para o Curso de Segurança do Trabalho no IFAL Campus São Miguel dos Campos corresponde a 66\% do total, e que a média de mulheres aprovadas equivale a $62 \%$ do total.

Essas informações reforçam a importância de se pensar a educação como promotora de pensamento crítico. As alunas superam uma história de preconceito e discriminação ao se fazerem presentes de forma significativa nos processos seletivos e nas salas de aula. Vemos uma educação que promova uma sociedade mais justa e equânime como uma oportunidade de efetivação da equidade na sociedade. Como diz Correa, apud Maio (2018), "a discussão sobre as desigualdades de gênero dentro da educação tem uma função libertadora para as identidades que destoam das regras sociais padronizadas" (Maio, 2018, p.12). O melhor sentido do feminismo interseccional, que constitui a luta contra as desigualdades sociais de raça, classe, gênero, sexualidade, idade, capacidade e etnia, ao discutir o lugar da mulher na sociedade, se dá conta de que as diferenças, todas elas, devem não apenas ser aceitas, mas celebradas, na construção de uma sociedade plural.

\section{Metodologia}

Para o desenvolvimento dessa pesquisa, foi utilizada como metodologia a pesquisa-ação, que "propõe uma ação deliberada de transformação de realidades, trazendo em seu arcabouço uma dupla proposta como objetivo: a transformação da realidade investigada e a produção do conhecimento" (Tanajura, Bezerra, 2015, p. 2).

Os instrumentos metodológicos escolhidos foram o questionário semiestruturado e a roda de conversa. O questionário semiestruturado, através de questões abertas, proporciona às participantes da pesquisa maior liberdade, e através das fechadas, confere ao pesquisador maior facilidade de tabulação dos dados. (Gil 1999, apud Chaer et al. 2011, p.260). O segundo método a ser utilizado, a roda de conversa, possibilitou às participantes da pesquisa discutir a experiência enquanto alunas, assim como sua inserção no estágio. Embora seja uma reinvenção de um espaço tradicional de troca de saberes, como ferramenta de investigação se revela bastante rica. Segundo Moura e Lima (2014, p. 95),

A conversa é um espaço de formação, de troca de experiências, de confraternização, de desabafo, muda caminhos, forja opiniões, razão por que a Roda de Conversa surge como uma forma de reviver o prazer da troca e de produzir dados ricos em conteúdo e significado para a pesquisa na área de educação. No contexto da Roda de Conversa, o diálogo é um momento singular de partilha, uma vez que pressupõe um exercício de escuta e fala. As colocações de cada participante são construídas a partir da interação com o outro, sejam para complementar, discordar, sejam para concordar com a fala imediatamente anterior (Moura, Lima, 2014, p. 95).

A pesquisa foi iniciada após a aprovação do Comitê de Ética em Pesquisa do CESMAC, em 8 de julho de $2020^{4}$. A etapa diagnóstica foi dividida em duas etapas. Na primeira, simultaneamente à pesquisa bibliográfica, foram procuradas a Direção Geral, a Chefia de Departamento, a Coordenação do Curso e a Coordenação do Apoio Acadêmico da Assistência Estudantil, para explicar como seria a pesquisa e solicitar a sua anuência por escrito, via e-mail, nos termos de autorização. Os questionários foram enviados no formato de formulários online, após contato com as alunas participantes da pesquisa via grupo virtual. Em seguida, os questionários foram enviados no formato de formulários online, após contato com as alunas via grupo virtual. Também foram realizadas três rodas de conversa de forma virtual: duas com a presença da diretora do Campus, duas pedagogas, professoras, alunas e ex-alunas (só mulheres), e a última com um professor e a turma do $4^{\circ}$ período 2021.1 (alunos e alunas). Desta forma, também houve a participação masculina na pesquisa.

Após terem sido aplicados os questionários online e acontecido as rodas de conversa, foi realizada a análise de conteúdo que, segundo Silva e Fossá (2015), 
é uma técnica de análise das comunicações, que irá analisar o que foi dito nas entrevistas ou observado pelo pesquisador. Na análise do material, busca-se classificá-los em temas ou categorias que auxiliam na compreensão do que está por trás dos discursos. (Bauer, Gaskell, 2002, apud Silva, Fossá, 2015, p.2)

Nessa etapa, as análises foram realizadas tomando como base as respostas das alunas ao questionário, organizadas em categorias de análise, que serão apresentadas a seguir.

\section{Resultados e Discussão}

Participaram desta pesquisa 25 alunas concluintes do Curso de Segurança do Trabalho do Campus São Miguel, uma amostragem expressiva, que equivale a mais de $50 \%$ do total de discentes matriculadas nas duas turmas concluintes do Curso de Segurança do Trabalho no semestre 2020.1.

O Campus de São Miguel dos Campos foi inaugurado em 2010 e passou desde então a ofertar o Curso Subsequente de Técnico em Segurança do Trabalho. A Prefeitura de São Miguel dos Campos cedeu um espaço dentro de uma escola municipal, uma instalação que é insuficiente para atender às necessidades do Campus e que deveria ser uma sede provisória, porém acabou sendo a única até este ano. A sede definitiva está pronta, e será inaugurada quando houver o retorno presencial.

O processo seletivo vem acontecendo duas vezes por ano, com 80 vagas ofertadas a cada semestre, sendo 40 no turno vespertino e 40 no turno noturno. A relação candidatos/vaga era maior no início do funcionamento do Campus. Desde então, tem havido uma diminuição de oferta de trabalho na região; várias usinas sucroenergéticas fecharam e a crise financeira afetou a cidade, como ao resto do Estado. Observando essa realidade, decidimos nesta pesquisa conhecer os motivos que levaram essas mulheres, agora concluintes, a escolher o Curso Subsequente de Segurança do Trabalho no IFAL São Miguel dos Campos.

Inicialmente, no Gráfico 1 podemos observar que as participantes da pesquisa se situam entre 19 e 38 anos. A maioria encontra-se na faixa etária entre 19 e 25 anos, um total de 21 alunas, representando uma porcentagem de $84 \%$ da amostra. As participantes acima de 25 anos representam $16 \%$.

Gráfico 1: Idade das discentes.

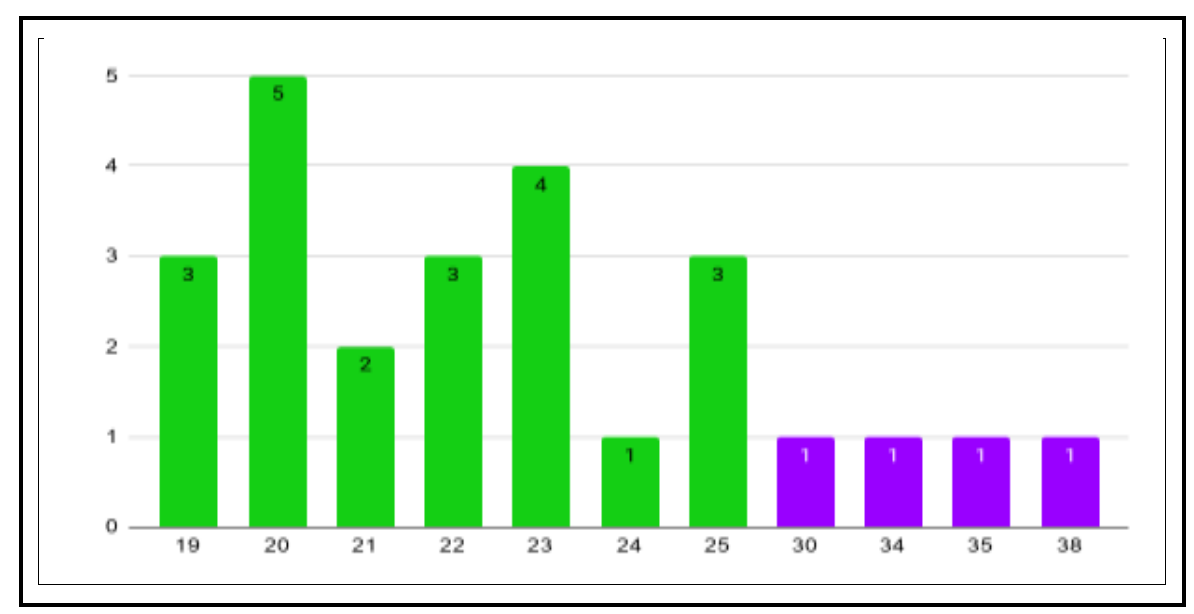

Fonte: Dados da pesquisa (2020).

Destacamos nesse momento as motivações que levaram as discentes a escolher o curso no IFAL. Procedendo à análise pela codificação em unidades de registro, classificamos na unidade de registro "nova profissão", como subcategoria inicial, as respostas das participantes que externaram essa escolha do curso de forma expressa. Também foram classificadas na unidade 
as respostas que utilizaram a palavra profissão, bem como palavras que estão contidas na denominação do curso de Segurança do Trabalho, como: segurança, trabalhador e ambiente do trabalho. Foram agrupadas na unidade de registro "mais conhecimento depois do ensino médio" as respostas que não expressaram uma escolha específica, falaram em conhecimento e enriquecimento educacional.

Assim, organizamos essas motivações em subcategorias dispostas no quadro a seguir.

Quadro 1: Motivação da escolha do curso.

\begin{tabular}{|l|l|}
\hline \multicolumn{1}{|c|}{ Unidades de registro } & \multicolumn{1}{c|}{ Respostas das participantes } \\
\hline \multicolumn{1}{|c|}{ Nova profissão } & $\begin{array}{l}\text { Para tentar entrar em uma boa profissão. } \\
\text { Antes de me inscrever no curso fui pesquisar mais sobre e gostei muito da profissão. } \\
\text { Por que é uma profissão em que quero trabalhar e exercitar as minhas experiências, e essa profissão e a mais } \\
\text { bela e responsável que eu já vi. } \\
\text { Para poder ter um curso técnico além da faculdade, para que futuramente se eu vir a precisar deste (como forma } \\
\text { de uma segunda profissão eu estarei assegurada). } \\
\text { Porque acho que o curso/profissão é de muita importância no ambiente do trabalho. } \\
\text { Para ter aprendizado sobre a área e ter uma oportunidade de trabalho. }\end{array}$ \\
\hline \multirow{3}{*}{$\begin{array}{l}\text { Mais conhecimento } \\
\text { depois do ensino médio }\end{array}$} & $\begin{array}{l}\text { Pelo desejo de obter conhecimento sobre questões que permeiam o ambiente laboral, para aperfeiçoar meu } \\
\text { carreira profissional futuramente. } \\
\text { Aprender novos conhecimentos. } \\
\text { Com o intuito de enriquecimento educacional e do meu currículo. }\end{array}$ \\
\hline
\end{tabular}

Fonte: Dados da pesquisa (2020).

Ao analisarmos os dados apresentados, vemos que a maioria expressiva das alunas está na faixa mais próxima do final do Ensino Médio, tendo optado pela escolha de uma formação profissional subsequente antes de cursar o ensino superior. As participantes com mais de 25 anos são mulheres que não continuaram seus estudos e evidenciam a importância do curso na região, ao atrair egressas do Ensino Médio distantes dos bancos escolares há muito tempo, de 12 a 20 anos, aproximadamente, após a idade regular de conclusão. Para essas mulheres, ser aprovada nesta seleção pode significar uma oportunidade de um futuro que muitas já não tinham esperança de alcançar, constituindo um recomeço e um desafio. Trata de uma qualificação profissional de qualidade com o tempo de duração mais curto em relação ao curso superior, e pode dar a formação necessária para o ingresso ou reingresso no mundo do trabalho.

Nessa outra questão, as participantes da pesquisa responderam que sentiram dificuldade nas atividades práticas externas ao IFAL, como visitas técnicas ou estágio, por ser mulher. 
Gráfico 2: Dificuldades por ser mulher nas atividades práticas.

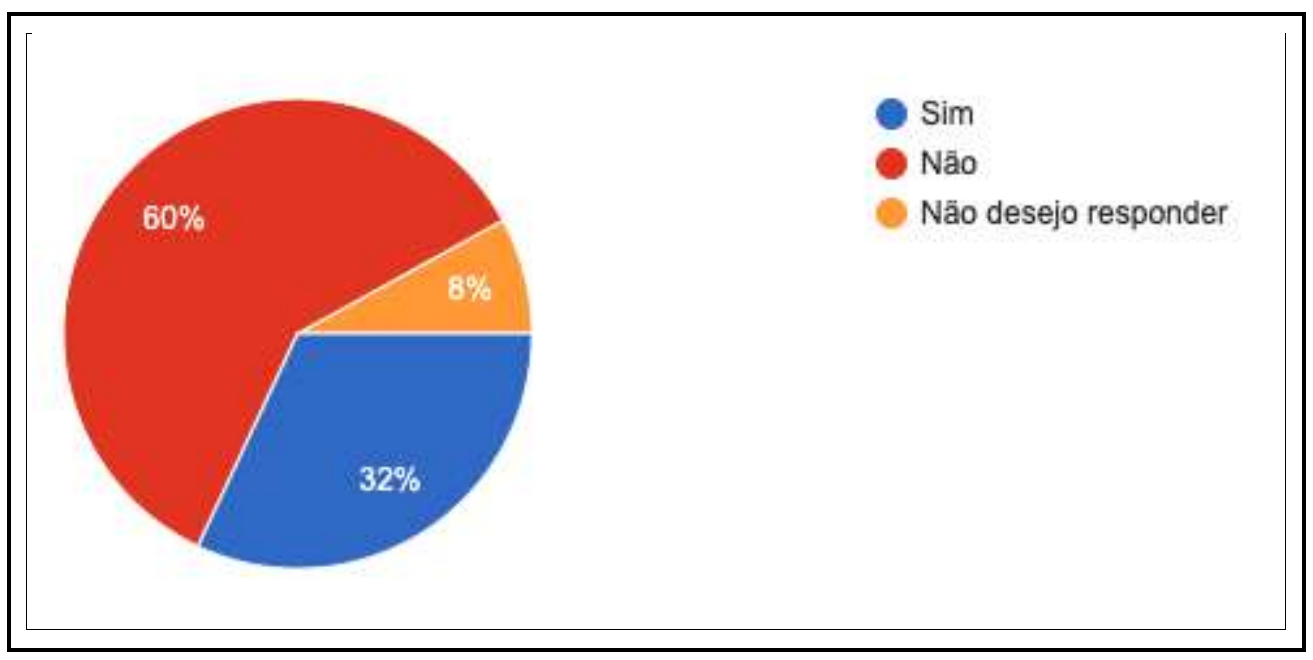

Fonte: Dados da pesquisa (2020).

Vemos a seguir a transcrição das descrições do tipo de dificuldade que encontraram as participantes da pesquisa que responderam "sim" à essa pergunta.

Quadro 2: Descrição das dificuldades.

\begin{tabular}{|c|c|}
\hline $\begin{array}{l}\text { Unidades de } \\
\text { registro }\end{array}$ & Respostas das participantes \\
\hline $\begin{array}{l}\text { Fragilidade do } \\
\text { gênero } \\
\text { feminino }\end{array}$ & $\begin{array}{l}\text { Acredito que por ser mulher a dificuldade para conseguir um estágio seja maior, pois ainda somos vistas como pessoas } \\
\text { frágeis e sem profissionalismo. } \\
\text { Empresas que "preferem" homens para realizar o estágio. } \\
\text { Só no estágio. } \\
\text { Sentir dificuldade no estagio. Por ser mulher não foi permitido explorar todas as áreas (ir ao campo, ter contato com os } \\
\text { trabalhadores de forma direta) nem utilizar o transporte com o técnico de segurança (devido a ser mulher). } \\
\text { Senti uma certa dificuldade no início do meu estágio por ser em uma usina mas logo fui conquistando o meu espaço } \\
\text { no local e graças a Deus e com a ajuda de todos do setor e os trabalhadores consegui desenvolver todas as minhas } \\
\text { atividade e de forma colaborativa por parte dos trabalhadores. Foi uma experiência maravilhosa! } \\
\text { Na maioria das visitas técnicas, só tinha técnico de segurança do trabalho homem. } \\
\text { Em uma visita técnica onde todos os trabalhadores eram homens, e por ser uma empresa que produz materiais de } \\
\text { construção e para isso eles explodem rochas, essa empresa é localizada em um local com muitas árvores, matos etc. Eu } \\
\text { particularmente me senti insegura de porventura chegar a trabalhar em um local desse e sofrer algum tipo de abuso, } \\
\text { assédio, por ser uma mulher rodeada por muitos homens onde eu teria que dá algumas instruções que cabe à mim } \\
\text { como TST. } \\
\text { Aulas técnica }\end{array}$ \\
\hline
\end{tabular}

Fonte: Dados da pesquisa (2020).

Nessa questão, foi relatada uma maior dificuldade por ser mulher (32\% do total de respostas) na área da colocação em prática do aprendizado, tanto na subcategoria "estágios" (62,5\%) como na subcategoria "em visitas técnicas" (37,5\%). 
A mulher vista como uma pessoa frágil e sem profissionalismo; ser preterida por ser mulher; não poder ir ao encontro dos trabalhadores no campo ou pegar um transporte com um técnico colega de trabalho por ele ser homem; medo de assédio ou estupro foram percepções explicitadas pelas participantes da pesquisa, como podemos ver nessa declaração: "Eu particularmente me senti insegura de por ventura chegar a trabalhar em um local desses (com muitas árvores, mato) e sofrer algum tipo de abuso, assédio" (questionário). Essa resposta abordou um medo feminino real e comum a mulheres de todos os estratos sociais. Os crimes sexuais (abuso, assédio, estupro etc.) são uma realidade perversa, minimizada, subnotificada, relativizada e, infelizmente, crescente em nosso país e em nossa região. A transformação da vítima em ré, em função de préjulgamentos, também acontece com muita frequência. Pela natureza do delito, muitas vezes o silêncio gera a impunidade e a repetição dos atos transgressores. Brilhante, Nations e Catrib (2019) abordam em seus estudos estatísticas alarmantes no que se refere as questões de gênero:

Das 9.049 notificações de violências e acidentes em 2006 e 2007, 33\% foram violências sexuais. No Brasil, em 2011, foram notificados 12.087 casos de estupro. Estima-se que $43 \%$ das mulheres brasileiras sofreram algum tipo de violência sexual ao longo da vida sendo que mais de $50 \%$ não pediram ajuda e que em $53 \%$ dos casos os maridos e parceiros foram os agressores e que anualmente $0,26 \%$ da população brasileira (cerca de 527 mil) sofre violência sexual, dos quais $10 \%$ são reportados à polícia.(...) $43 \%$ das mulheres sofreram algum tipo de violência sexual, sendo que mais de $50 \%$ não pediram ajuda e que em $53 \%$ dos casos os maridos e parceiros foram os agressores 4; que o Brasil é o $5^{\circ}$ país do mundo em feminicídio e que dos 4.762 assassinatos de mulheres registrados em 2013 no Brasil, 50,3\% foram cometidos por familiares (incluindo parceiros e ex-parceiros em 33,2\%) (Brilhante, Nations, Catrib, 2019, p. 2).

As rodas de conversa propiciaram a confirmação dos dados levantados no questionário sobre dificuldades no estágio por ser mulher. Na Roda de conversa 1, uma aluna fala sobre dificuldades em um estágio, que foram vencidas a partir da sua postura. Eis a transcrição do seu relato

Eu queria ir pro campo, eu peguei no primeiro mês o conhecimento teórico, no estágio, vendo tudo, e depois quando eu encontrava com o engenheiro, eu solicitava: "Eu quero ir, eu preciso ir, de que adianta eu estar em um estágio tão rico que é o estágio em uma usina e eu não poder participar de todas as áreas?”. Teve muita coisa no estágio que eu, enquanto estagiária mulher, não pude fazer, enquanto eles visitaram alguns setores e fizeram algumas atividades que simplesmente eu não podia fazer. E o engenheiro só alegava que era por conta de eu ser mulher: 'Não, porque você é mulher, aí tem os trabalhadores e podem não respeitar' e vinha com essas desculpas. Aí eu aperreei, eu aperreei e nos últimos 15 dias ele deixou eu ir pro campo, acompanhada do técnico, ele não liberou pra eu fazer tudo, mas os técnicos de lá são muito bons, então eles viam em mim essa questão de querer fazer, de querer aprender e eles deixaram eu ir entregar, ter contato com o trabalhador. Porque o engenheiro falava só assim: 'Leve ela mas mantenha ela distante, não deixe muito ela ter contato com o trabalhador, porque você sabe que os trabalhadores faltam com o respeito'. Enquanto que os meninos já viam o meu posicionamento e falavam: 'Você quer, você tem certeza?' E eu dizia: 'Eu tenho, eu vou'. Aí eu consegui fazer alguns trabalhos nesses últimos dias de estágio por conta que eu fiquei pressionando muito pra ir, pra conhecer mesmo e ter contato com o trabalhador.

Podemos analisar esta situação como uma vitória pessoal, que ela mesma relata como uma experiência maravilhosa. Porém será necessário esse dispêndio de energia e de poder pessoal, de convencimento e conquista? E se uma colega, com as mesmas credenciais profissionais, for vencida pelas condições adversas, por reagir de forma diferente à pressão psicológica? É possível compreender como a relação entre o responsável pelo estágio e a aluna poderia ser diferente a partir de uma visão mais compreensiva da função da empresa como promotora do estágio, a de formar trabalhadores/as competentes e bem informados, com iniciativa e visão ampla da função a ser exercida.

Marisa Ramos assim analisa como se realiza um jogo dialético que irá influir no trabalho, histórica e socialmente

do modo de produção da existência, [a educação profissional] implica um fenômeno em que estão em relação histórica, tensa e contraditória: distintas necessidades dos sujeitos e das classes sociais; o trabalho se realizando como 
produtor de valor de uso e valor de troca, como criação humana e como alienação, como potencial humano e como mercadoria; a ciência como força produtiva e como força destrutiva; a tecnologia como meio de libertação e de opressão humana, como geradora de tempo livre ou de miséria, dentre outras. (Ramos, 2013, p.30)

No texto da pesquisa Taca cachaça que ela libera (Brilhante, Nations, Catrib, 2019, p.1), podemos ler que a violência contra a mulher é "uma questão de valores culturais hierárquicos de gênero produzidos socialmente". Os Institutos Federais proporcionam uma formação técnica de qualidade, baseado no tripé ensino, pesquisa e extensão. $\mathrm{O}$ acesso à pesquisa e extensão, a professores com sólida formação, confere aos alunos o alargamento de horizontes, que muitas vezes os/as leva à continuação dos estudos após a conclusão do curso subsequente. Segundo Bonamigo, o ensino profissional baseado na educação omnilateral, como acontece nos Institutos Federais, concebe o trabalho como princípio e processo educativo. Desta forma, continua ele, ao ser vinculado às práticas produtivas, à consciência e definição dos fins das ações humanas, ao domínio intelectual, o trabalho "abre-se para a possibilidade de um processo de formação humana em todas as dimensões, para a transformação e a emancipação do ser humano" (Bonamigo, 2014).

Nesse sentido, é importante lembrar que ingressar no IFAL, uma escola pública que busca a qualidade social nos seus diversos cursos de qualificação profissional, possibilita a essas discentes um olhar diferenciado sobre seus direitos. Entre esses direitos, inscreve-se de forma relevante o direito das mulheres a serem tratadas com igualdade e respeito na escola e no trabalho. Sobre essa questão, trazemos a seguinte contribuição de Souza e Lima Neto (2019, p.240):

O compromisso com a emancipação humana, individual e coletiva não pode ser dissociado daquilo que atinge todas as dimensões materiais da existência, nela inclusos os usos sociais do corpo, inteiramente atravessado pelo pertencimento de classe, e as interações simbólicas nas quais ele está imerso, como aquelas operadas na feitura do gênero (Souza, Lima Neto, 2019, p. 240)

Diante desses dados, e de tudo o que foi discutido até o momento, podemos destacar dois aspectos essenciais. O primeiro aspecto diz respeito à questão de que o Curso Técnico subsequente para essas discentes no interior de Alagoas é, possivelmente, a única chance de mudar uma realidade social, mudar a "profissão", uma vez que diversos motivos não permitiram a continuidade dos seus estudos através do ensino superior. Já o segundo aspecto remete à questão de que a parte prática do curso (estágio e visitas técnicas) apresenta maiores dificuldades para as alunas pelo fato de serem mulheres, pela postura das empresas onde acontecem os estágios e as visitas técnicas de limitar a ida das estagiárias ao campo.

\section{Considerações Finais}

A mulher estuda mais, trabalha mais e ganha menos do que o homem. Possuindo mais anos de escolaridade e trabalhando mais horas, ela ainda recebe, em média, $76,5 \%$ do salário que o homem perfaz.

Nas últimas décadas, a força das mulheres no mundo do trabalho ocorre com uma significativa transformação. A necessidade de cooperar com o orçamento familiar e a ascensão do seu nível educacional fizeram da mulher um componente essencial no desenvolvimento da força do trabalho do mundo contemporâneo. "A inserção da mulher no sistema produtivo constitui um dado privilegiado para a análise das transformações que vêm ocorrendo com o feminino na modernidade" (Gomes, 2005, p.8).

A escolha deste tema revela-se de importância para os profissionais da educação, para os/as discentes e para a sociedade como um todo. Sem o pleno envolvimento educacional, social e político das mulheres e de todas as diversidades, de gênero, etnia, classe, teremos uma sociedade a meio caminho do seu pleno desenvolvimento: "Refletir sobre como construímos nossa história, nossa sociedade e as relações entre mulheres e homens é sempre necessário para a busca para um mundo com maior justiça social, com maior igualdade entre os gêneros" (Da Silva, 2019, p.129). 
A pesquisa aqui iniciada enseja desdobramentos no sentido de ampliar o seu olhar para considerar, a partir da escolha da profissão e da inserção no estágio, a experiência vivida e as discussões que podem surgir entre os/as atores envolvidos. Pretendemos exibir os resultados em reuniões com a comunidade escolar e discutir os dados da pesquisa no sentido de facilitar a experiência prática das mulheres no curso, dando a conhecer a todos e todas as experiências das alunas nos estágios, visando gerar uma experiência de estágio mais diversificada, que pode levar a uma melhor empregabilidade. Este aprendizado tem a finalidade de favorecer o fortalecimento da equidade de gênero no IFAL e na sociedade, usando a própria fala das alunas, sua percepção e suas vivências.

\section{Referências}

Bezerra, A. A. C., \& Tanajura, L. L. C. (2015). A Pesquisa-ação sob a ótica de René Barbier e Michel Thiollent: aproximações e especificidades metodológicas. Revista eletrônica pesquiseduca, 7(13), 10-23.

Bonamigo, C. A. (2014). Limites e possibilidades históricas à educação omnilateral. Educere-Revista da Educação da UNIPAR, 14(1).

Brasil (2017), Lei 9394/1996 (Lei de Diretrizes e Bases da Educação Nacional). Senado Federal. https://www2.senado.leg.br/bdsf/handle/id/529732 .

Brasil (2018), Instituto Brasileiro de Geografia e Estatística (IBGE). Mulher estuda mais, trabalha mais $e$ ganha menos do que o homem. https://agenciadenoticias.ibge.gov.br/agencia-noticias/2012-agencia-de-noticias/noticias/20234-mulher-estuda-mais-trabalha-mais-e-ganha-menos-do-que-ohomem .

Brasil (2018) Instituto Nacional de Estudos e Pesquisas Educacionais Anísio Teixeira (INEP). Mulheres são maioria na educação profissional e nos cursos de graduação, 2018b. http://portal.inep.gov.br/artigo/- /asset_publisher/B4AQV9zFY7Bv/content/mulheres-sao-maioria-na-educacao-profissional-e-nos-cursosde-graduacao/21206

Brasil (2020) Tribunal Superior Eleitoral (TSE). https://www.tse.jus.br/imprensa/noticias-tse/2020/Fevereiro/dia-da-conquista-do-voto-feminino-no-brasil-ecomemorado-nesta-segunda-24-1.

Brilhante, A. V. M., Nations, M. K., \& Catrib, A. M. F. (2018). "Taca cachaça que ela libera": violência de gênero nas letras e festas de forró no Nordeste do Brasil. Cadernos de Saúde Pública, 34 .

Chaer, G., Diniz, R. R. P., \& Ribeiro, E. A. (2012). A técnica do questionário na pesquisa educacional. Revista Evidência, 7(7).

da Silva, L. L. T. (2019). Mulheres e o mundo do trabalho: a infindável dupla jornada feminina. Revista Eletrônica Interações Sociais, 3(1), $120-131$.

Daniel, C. (2011). O trabalho e a questão de gênero: a participação de mulheres na dinâmica do trabalho. O social em questão, (25/26), 323-344.

Engels, F. (1984). A origem da família, da propriedade privada e do Estado. Civilização Brasileira.

Federici, S. (2017). Calibã e a bruxa: mulheres, corpos e acumulação primitiva. Editora Elefante.

Gomes, A. F. (2005). O outro no trabalho: mulher e gestão. REGE Revista de Gestão, 12(3), 1-9.

Luxemburgo, R. A proletária.Textos escolhidos vol. I. Organizado por Isabel Loureiro - Editora UNESP, páginas 493-496. https://www.marxists.org/portugues/luxemburgo/1914/03/05.htm

Maio, E. R. (2018). Gênero e Sexualidade: Interfaces Educativas. Appris Editora e Livraria Eireli-ME.

Nascimento, S. D. (2014). Precarização do trabalho feminino: a realidade das mulheres no mundo do trabalho. Temporalis, 14(28), 39-56.

Quirino, R. (2012). Trabalho da mulher no Brasil nos últimos 40 anos. Revista Tecnologia e Sociedade, 8(15), 90-102.

Ramos, M. N. (2013). Trabalho e educação: implicações para a produção do conhecimento em Educação Profissional. Produção de conhecimento, políticas públicas e formação docente em educação profissional. Campinas, SP: Mercado de Letras, 23-40.

Saffioti, H. (2013). A mulher na sociedade de classes - mito e realidade. Expressão Popular, (3a ed.).

Silva, A. H., \& Fossá, M. I. T. (2015). Análise de conteúdo: exemplo de aplicação da técnica para análise de dados qualitativos. Qualitas Revista Eletrônica, 16(1).

Souza, L. M., \& de Lima Neto, A. A. (2019). Fazendo Gênero Na Educação Profissional: notas epistemológicas a partir do estado de conhecimento sobre educação profissional e gênero na Biblioteca Digital Brasileira de Teses e Dissertações (2008-2019). Cadernos de Pesquisa, 235-250.

Sousa, L. P. D., \& Guedes, D. R. (2016). A desigual divisão sexual do trabalho: um olhar sobre a última década. Estudos avançados, 30 , $123-139$.

Pereira, M. F. V. (2010). A inserção subordinada do Brasil na divisão internacional do trabalho: consequências territoriais e perspectivas em tempos de globalização. Sociedade \& Natureza, 22, 347-355. 